\title{
Intramedullary nailing for correction of post-traumatic deformity in late-diagnosed distal radius fractures
}

\author{
Alvin Chao-Yu Chen ${ }^{1} \mathbb{C} \cdot$ Chun-Ying Cheng ${ }^{1} \cdot$ Ying-Chao Chou $^{1}$
}

Received: 8 September 2015/Accepted: 9 July 2016/Published online: 26 July 2016

(c) The Author(s) 2016. This article is published with open access at Springerlink.com

\begin{abstract}
Background Post-traumatic deformity of the distal radius may lead to multiple sequelae and severe functional impairment. Intramedullary fixation is a novel technique for treatment of distal radius fractures. The present study aimed to evaluate the functional and radiographic outcomes of intramedullary nailing for correction of posttraumatic deformity in late-diagnosed fractures of the distal radius.

Materials and methods From July 2009 to February 2011, 16 patients with late-diagnosed displaced fractures of the distal radius were included. Eligible inclusion was extraarticular fracture for more than 4 weeks. Surgical correction and internal fixation with intramedullary nailing was performed for treatment of ten AO type A2 and six AO type A3 fractures. All patients were followed up radiographically and clinically for an average of 20.3 months.

Results All fractures achieved bone union without major complications. Functional status and radiographic alignment significantly improved postoperatively. There was no significantly secondary displacement comparing early postoperative and final radiographic parameters. The functional results according to the Mayo wrist scoring system were good or excellent in $94 \%$ of patients. The mean score was 83.8.

Conclusion Surgical correction and internal fixation with the intramedullary nail is a feasible and less invasive
\end{abstract}

Alvin Chao-Yu Chen

alvinchen@cgmh.org.tw

1 Bone and Joint Research Center, Chang Gung Memorial Hospital-Linkou \& University College of Medicine, 5th, FuShin St., Kweishan Dist, Taoyuan 333, Taiwan, ROC technique with few complications in the treatment of posttraumatic deformity of the distal radius.

Level of evidence IV.

Keywords Distal radius · Extra-articular fracture .

Malunion $\cdot$ Intramedullary fixation

\section{Introduction}

Distal radius fractures are one of the most common upper extremity injuries, accounting for about $8-15 \%$ of all skeletal injuries treated by orthopedic surgeons [1-3]. Latediagnosed fractures are frequently complicated with many sequelae; among them, malunion and post-traumatic wrist arthritis due to post-traumatic distal radius deformity are most frequently seen [4-6]. Common deformities following an extra-articular distal radius fracture include loss of the normal volar tilt of the articular surface in the saggital plane, decreased ulnar inclination in the frontal plane, and loss of length relative to the ulna [6]. Post-traumatic deformity results in alteration of normal anatomy, biomechanics of distal radius, and functional impairment in hand and wrist [6-8]. Many surgical modalities in the treatment of acute fractures of the distal radius have been proposed $[9,10]$. Intramedullary nailing is currently used to treat unstable extra-articular fractures of the distal radius [11]. Bearing the advantages of allowing load transfer across the fracture site and lessening soft-tissue dissection, intramedullary fixation can be used to stabilize the fracture bones through a less invasive approach and maintain periosteal vascular blood supply to promote fracture healing [12]. The purposes of this retrospective study were to describe our experience with mini-open osteotomy, local bone grafting, and fracture stabilization with the intramedullary nail 
device for treatment of post-traumatic deformity in latediagnosed fractures of the distal radius. Clinical outcomes, radiographic analysis, and complications were reported.

\section{Materials and methods}

In total, 16 consecutive patients (Table 1) with displaced extra-articular distal radius fractures (Fig. 1) and injured for more than 4 weeks were treated with mini-open wedge osteotomy (Fig. 2) and intramedullary fixation device (Micronail $^{\circledR}$, Wright Medical Technologies, Arlington, TN, USA), from July 2009 through February 2011 by a single surgeon. There were 5 men and 11 women, with an average age of 61.8 years (range 49-81 years). The fracture involved 5 right wrists and 11 left wrists in equal numbers of patients. According to the AO fracture classification [13], there were 10 AO type A2 and 6 AO type A3 fractures. The mechanisms of injury in all patients were either a simple fall on the outstretched hand or a traffic accident. The mean time from injury to surgery was 10.7 weeks (range 4-18 weeks). All patients had regular follow-up in our outpatient clinic for at least 12 months.

\section{Surgical procedure}

A 2-cm longitudinal incision was made medial to Lister's tubercle on the dorsal wrist. An open-wedged osteotomy was performed through the malunion site using a 5-mm osteotome, and transfixed provisionally with Kirschner wires after manual reduction under $\mathrm{C}$-arm fluoroscopic assistance. A second 1-cm incision was made over the radial styloid, followed by blunt soft-tissue dissection and meticulous protection of the superficial radial sensory nerve. Dissection through the interval of the first and second dorsal extensor compartments was made using a starter awl in order to create a cortical bone window. This was followed by tapping sequential broaches into the intramedullary canal until the proper fit was achieved (Fig. 2). After sizing and trialing, a Micronail ${ }^{\circledR}$ of the measured size was gently inserted through the pre-taped track into the medullary canal of the distal radius. Three distal fixed-angle locking screws and two proximal interlocking screws were then applied through the guiding system. After satisfactory realignment and secure fixation were confirmed by fluoroscopy, all provisionally transfixed Kirschner wires were removed and the guide system was disassembled from the intramedullary nail. Local callus from the nascent malunion was morselized to serve as a bone graft for the osteotomy site in 14 patients $(87.5 \%)$. Two patients $(12.5 \%)$ needed additional artificial bone graft substitutes due to insufficient local bone graft. The wound was closed layer by layer. A volar short arm splint was applied for protection after dressing the wound.

Table 1 Patient demographic data

\begin{tabular}{|c|c|c|c|c|c|c|c|}
\hline Patient no. & Age (years) & Sex & Wrist & $\begin{array}{l}\text { AO fracture } \\
\text { classification }\end{array}$ & $\begin{array}{l}\text { Time to surgery } \\
\text { (weeks) }\end{array}$ & $\begin{array}{l}\text { Bone union } \\
\text { (weeks) }\end{array}$ & $\begin{array}{l}\text { Follow-up } \\
\text { (months) }\end{array}$ \\
\hline 1 & 65 & $\mathrm{~F}$ & Left & A2 & 4 & 12 & 32 \\
\hline 2 & 64 & M & Left & A2 & 16 & 6 & 28 \\
\hline 3 & 69 & $\mathrm{~F}$ & Left & A3 & 8 & 8 & 30 \\
\hline 4 & 81 & M & Left & A2 & 6 & 6 & 24 \\
\hline 5 & 58 & $\mathrm{~F}$ & Left & A2 & 10 & 8 & 32 \\
\hline 6 & 59 & $\mathrm{~F}$ & Left & A2 & 7 & 6 & 12 \\
\hline 7 & 49 & M & Right & A3 & 16 & 6 & 20 \\
\hline 8 & 58 & $\mathrm{~F}$ & Left & A2 & 9 & 6 & 18 \\
\hline 9 & 71 & $\mathrm{~F}$ & Left & A3 & 7 & 8 & 16 \\
\hline 10 & 67 & M & Left & A3 & 4 & 6 & 16 \\
\hline 11 & 49 & $\mathrm{~F}$ & Left & A2 & 13 & 7 & 12 \\
\hline 12 & 55 & $\mathrm{~F}$ & Right & A2 & 18 & 6 & 16 \\
\hline 13 & 62 & $\mathrm{~F}$ & Right & A3 & 10 & 7 & 18 \\
\hline 14 & 57 & $\mathrm{M}$ & Right & A2 & 14 & 6 & 14 \\
\hline 15 & 66 & $\mathrm{~F}$ & Left & A2 & 18 & 12 & 18 \\
\hline 16 & 59 & $\mathrm{~F}$ & Right & A3 & 11 & 12 & 18 \\
\hline Mean & 61.8 & & & & 10.7 & 7.6 & 20.3 \\
\hline SD & 8.2 & & & & 4.7 & 2.3 & 6.8 \\
\hline
\end{tabular}

$S D$ standard deviation 
Fig. 1 A 69-year-old female patient. Radiographs of left wrist at 6 weeks after injury radius with malalignment show fracture of the distal

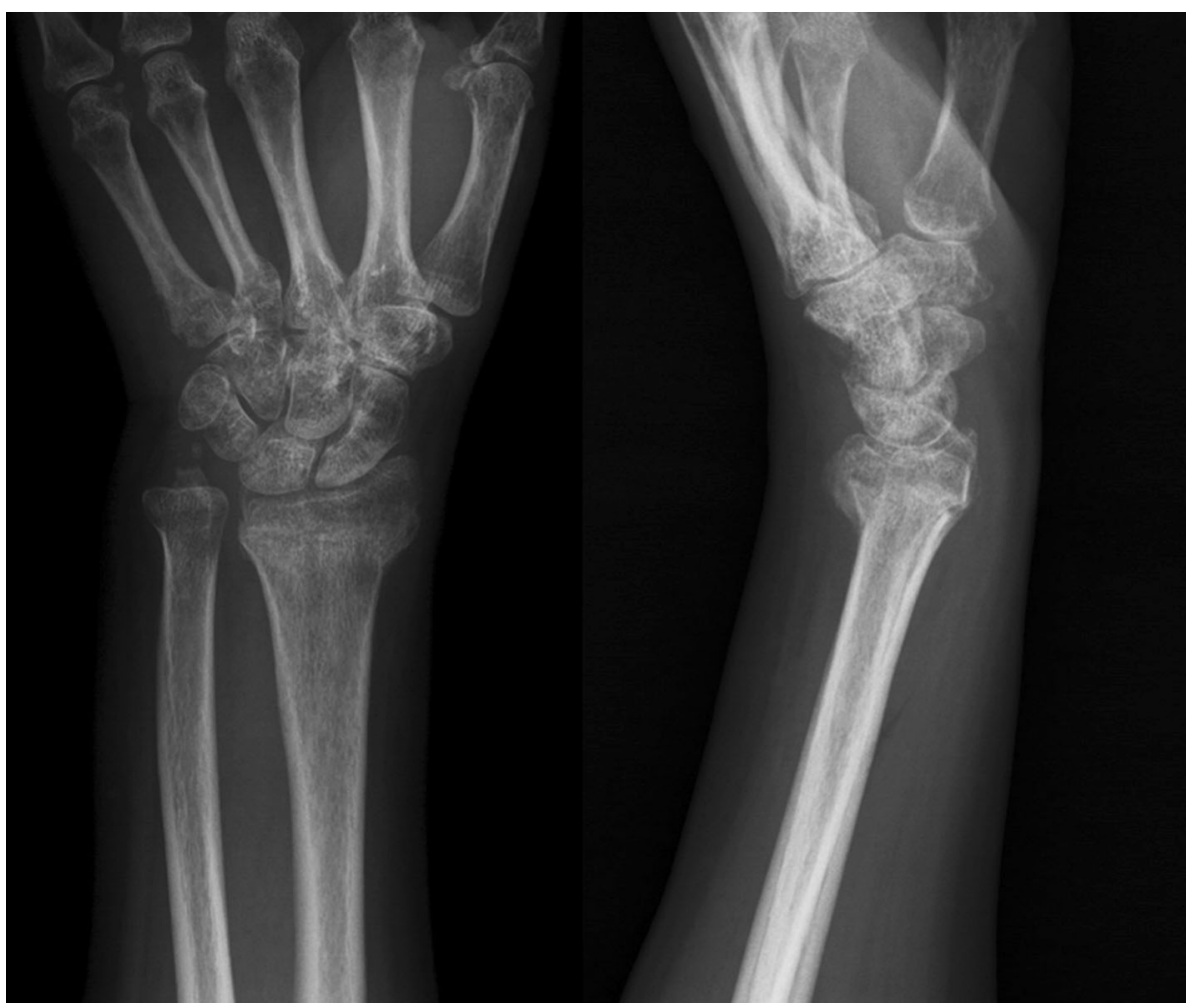

Fig. 2 Intra-operative C-arm images show correction of deformity through mini-open osteotomy and provisional Kirschner wire fixation (hollow arrow), and intramedullary preparation by broach taping

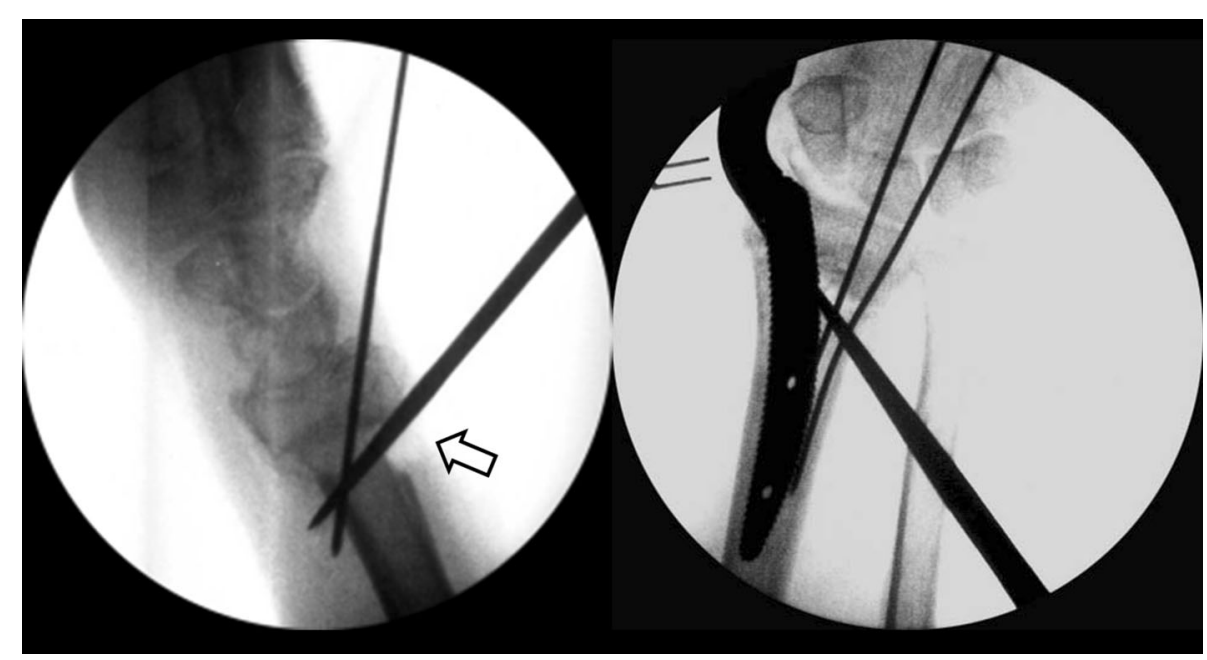

\section{Postoperative evaluation and follow-up}

All patients had a short arm splint for temporary protection postoperatively. To avoid stiffness and reduce swelling, postoperative rehabilitation with active finger, elbow, and shoulder range of motion training was started immediately postoperatively. Patients were typically seen for their first postoperative visit at 10-14 days. At that visit, the short arm splint and sutures were removed and unrestricted active range of motion was allowed for the wrist. Posterior-anterior and lateral radiographs of the injured wrist were performed preoperatively, then monthly for 3 months, and then every 3 months until 1 year after surgery. Three radiographic parameters, radial height, radial inclination, and volar tilt, were recorded. Bone healing was evaluated and radiographic union was confirmed with trabecular bridging of fracture. The statistical analysis was a 2-sample $t$ test to determine the significance of the radiographic parameters between postoperative radiographs and those of the 1-year follow-up. Significant difference was defined as a $p$ value less than 0.05 .

Functional evaluation was performed using the modified Mayo wrist scoring system. Grip strength of the injured 
side was measured and reported as a percentage of maximal strength of the contralateral side. The pain scale was self-reported and graded with the use of a questionnaire. With the addition of the satisfaction score, a modification of the Mayo Wrist Scoring Chart was used for functional assessment, allowing for a total count of 100 points in four categories [14].

\section{Results}

The average follow-up period was 20.3 months (range 12-32 months). All 16 patients resumed hand and wrist motion and had healed fractures (Fig. 3). The mean osseous healing time was 7.6 weeks (range 6-12 weeks) after surgery. All measurements of grip strength, range of motion, pain, and functional scores were significantly improved at the 1-year follow-up compared with preoperative status (Table 2). The overall clinical and functional results according to the modified Mayo wrist scoring system were excellent in 8 patients (50\%), good in 7 patients (44\%), and fair in $1(6 \%)$. All achieved satisfactory functional outcome. The mean Mayo score was improved from 41.9 (range 20-65) preoperatively to 83.8 (range 70-100) at final follow-up.

All the measurement of postoperative radiographic parameters showed significant improvement compared with preoperative status (Table 3). Radial height improved from an average of $8.0 \mathrm{~mm}$ (range 6-12) preoperatively to $12.1 \mathrm{~mm}$ (range 7-19) postoperatively. Radial inclination improved from an average of $16.4^{\circ}$ (range 3-24) preoperatively to $21.9^{\circ}$ (range $16-30$ ) postoperatively. Volar tilt improved from an average of $4.0^{\circ}$ (range -30 to 11 ) preoperatively to $11.2^{\circ}$ (range -10 to 11 ) postoperatively. No significant secondary displacement was found when comparing all the three parameters between early postoperative status and the final follow-up.

There was no major complication such as wound infection, loss of reduction, implant failure, or complex regional pain syndrome. Minor complications included four patients with transient superficial radial nerve irritation. The symptoms resolved gradually in the early followup period. There was no case of screw penetration into the radiocarpal or distal radioulnar joint.

\section{Discussion}

The primary goal in treatment of post-traumatic deformity of the distal radius is to restore anatomical alignment and prevent secondary displacement. Traditionally, extra-articular osteotomy is performed to re-establish volar tilt in the saggital plane and radial inclination in the coronal plane, correct any rotational malalignment in the horizontal plane, and restore radial length $[14,15]$. Several fixation modalities are available for distal radius osteotomy.
Fig. 3 Radiographs at 6 months after surgery show osseous union and consolidation of osteotomy site (white arrow)

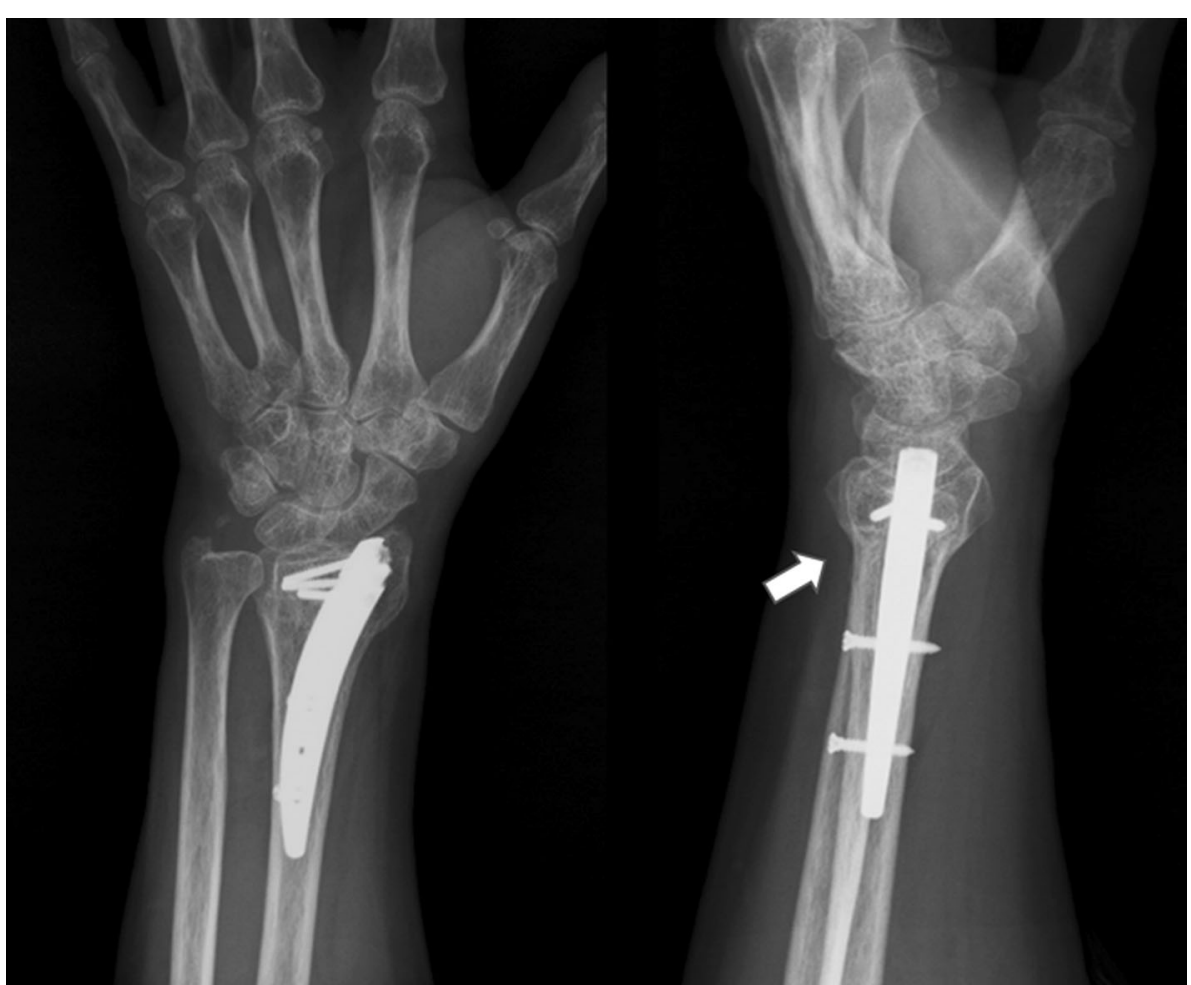


Table 2 Statistical summary of functional outcomes

\begin{tabular}{llllllll}
\hline & $\begin{array}{l}\text { Grip strength }(\mathrm{kg}), \\
\text { mean }(\mathrm{SD})\end{array}$ & \multicolumn{2}{l}{ Range of motion $\left(^{\circ}\right)$} & & $\begin{array}{l}\text { Pain } \\
\text { VAS }\end{array}$ \\
\cline { 3 - 6 } & & $\begin{array}{l}\text { Extension, mean } \\
(\mathrm{SD})\end{array}$ & $\begin{array}{l}\text { Flexion, mean } \\
(\mathrm{SD})\end{array}$ & $\begin{array}{l}\text { Supination, mean } \\
(\mathrm{SD})\end{array}$ & $\begin{array}{l}\text { Pronation, mean } \\
(\mathrm{SD})\end{array}$ & $\begin{array}{l}\text { Functional } \\
\text { outcome } \\
\text { Mayo, mean } \\
(\mathrm{SD})\end{array}$ \\
\hline Preoperative $^{\mathrm{a}}$ & $10.8(2.9)$ & $35.6(13.4)$ & $39.7(9.7)$ & $22.2(6.6)$ & $73.1(8.1)$ & $1.2(0.7)$ & $41.9(14.6)$ \\
Postoperative $^{\mathrm{a}}$ & $22.6(6.2)$ & $71.3(12.4)$ & $62.6(12.6)$ & $76.6(10.1)$ & $81.9(9.5)$ & $0.3(0.4)$ & $83.8(10.9)$ \\
$p$ value & $<0.001$ & $<0.001$ & $<0.001$ & $<0.001$ & $<0.001$ & $<0.001$ & $<0.001$ \\
\hline
\end{tabular}

$S D$ standard deviation, $V A S$ visual analogue scale

${ }^{a}$ At 1-year follow-up

Table 3 Statistical summary of radiographic findings

\begin{tabular}{|c|c|c|c|c|c|c|c|c|c|}
\hline & \multicolumn{3}{|c|}{ Radial height (mm) } & \multicolumn{3}{|c|}{ Radial inclination $\left(^{\circ}\right)$} & \multicolumn{3}{|c|}{ Volar tilt $\left(^{\circ}\right)$} \\
\hline & Preop & Postop & 1-year & Preop & Postop & One year & Preop & Postop & 1-year \\
\hline Mean & 8.0 & 12.1 & 11.2 & 16.4 & 21.9 & 21.1 & 4.0 & 11.2 & 4.8 \\
\hline SD & 2.6 & 3.4 & 10.4 & 5.7 & 3.8 & 2.9 & 4.2 & 3.1 & 3.9 \\
\hline$p$ value $^{\mathrm{a}}$ & 0.001 & 0.079 & & 0.001 & 0.200 & & $<0.001$ & 0.424 & \\
\hline
\end{tabular}

Preop preoperative, Postop postoperative

${ }^{a} p$ value, comparison between preop and postop status, and between postop and 1-year status

Osteosynthesis with dorsal and/or volar plates needs sufficient exposure to facilitate direct visualization, accurate reduction, and secure plating fixation. Common criticisms exist regarding wide soft-tissue dissection, tendon complication including tenosynovitis or tendon rupture, and prominence of hardware with internal fixation plate. Many patients need subsequent removal of the implant [16-18]. Intramedullary nails for fixation of the distal radius are intended to minimize those complications in treatment of post-traumatic deformity of distal radius [19]. With the benefits of limited soft-tissue dissection, a low-profile implant with less risk of tendon attrition, divergent subchondral screw placement, and locked fixed-angle fixation, the intramedullary nail serves as an internal splint to provide sufficient stability, allow immediate active motion at the fracture site and acquire healing through peripheral callus remodeling [11, 20, 21].

Traditionally, open wedge osteotomy is a commonly adapted procedure in correction of distal radius deformity $[22,23]$. Autogenous iliac crest cancellous or corticocancellous bone graft is used to fill the gap and provide mechanical support after open wedge osteotomy. Several problems have been identified regarding this approach, including donor site morbidity, delayed union at the bonegraft interfaces, and size mismatch between the graft and the osteotomy defect $[24,25]$. In dealing with the posttraumatic deformity of distal radius in our series, osteotomy was performed through the identifiable fracture line of the nascent malunion. The local callus was morselized and served as bone graft to fulfill the osteotomy gap. Additional artificial bone graft substitutes may be used as an adjunct in case of insufficient local bone graft, and thus may decrease surgical time and donor site morbidity.

In this study, most patients (94\%) had excellent or good outcomes, which showed comparable results with other series [26-28]. One patient $(6 \%)$ did not receive any definite management until 13 weeks after injury, and showed only fair results. Inferior outcome could be attributed to soft-tissue contracture and wrist stiffness after prolonged immobilization, and delayed fracture healing after osteotomy [29]. Performing correction osteotomy with intramedullary nail fixation for post-traumatic distal radius deformity at an earlier stage may help prevent maladaptive soft-tissue contractures and arthrosis of the distal radio-ulnar joint [30].

Potential complications of intramedullary nail fixation using Micronail ${ }^{\circledR}$ may include dorsal superficial radial sensory nerve injury, soft-tissue irritation with screw heads, and screw penetration into the articular surface [20, 21]. Those complications are uncommon. None of the above complications occurred in our series. None of our patients presented residual paresthesia or neurological sequelae. Normally, the superficial radial sensory nerve may be present in the surgical field and is highly susceptible to injury. It is recommended that the superficial radial sensory nerve be identified and protected throughout the surgical procedure. There were no cases of infection, complex regional pain syndrome, hardware failure, or soft-tissue irritation in our series.

The limitations of this study include the small sample size with limited patient numbers, and short-term follow-up period. Further prospective and long-term studies would be 
helpful to delineate the effect on outcome of the timing of stabilization. In addition, larger outcome studies with direct comparison to other osteosynthesis techniques are necessary to better evaluate the efficacy of intramedullary nail fixation in correction of post-traumatic radius deformity.

In conclusion, intramedullary nail fixation for correction of post-traumatic deformity of the distal radius is a less invasive technique which can provide satisfactory reduction and stable fixation. Surgical osteosynthesis with local callus bone grafting is a feasible and effective management option with satisfactory radiographic and functional outcomes.

\section{Compliance with ethical standards}

Ethical standards The research protocols have been approved by the Institutional Review Board in our hospital, and have therefore been performed in accordance with the ethical standards laid down in the 1964 Declaration of Helsinki and its later amendments.

All patients' informed consents have been obtained.

No benefits in any form have been received or will be received from a commercial party related directly or indirectly to the subject of this article.

Conflict of interest The authors report no conflict of interest.

Open Access This article is distributed under the terms of the Creative Commons Attribution 4.0 International License (http://crea tivecommons.org/licenses/by/4.0/), which permits unrestricted use, distribution, and reproduction in any medium, provided you give appropriate credit to the original author(s) and the source, provide a link to the Creative Commons license, and indicate if changes were made.

\section{References}

1. Jupiter JB, Masem M (1998) Reconstruction of post-traumatic deformity of the distal radius and ulna. Hand Clin 4:377-390

2. Jupiter JB (1991) Current concepts review: fractures of the distal end of the radius. J Bone Joint Surg Am 73:461-469

3. Jupiter JB (1997) Complex articular fractures of the distal radius: classification and management. J Am Acad Orthop Surg 5:119-129

4. Chen NC, Jupiter JB (2007) Management of distal radial fractures. J Bone Joint Surg Am 89:2051-2062

5. Amadio P, Botte M (1987) Treatment of malunion of the distal radius. Hand Clin 3:541-559

6. Tang JB, Ruy J, Omokawa S, Han J, Kish V (1994) Biomechanical evaluation of wrist motor tendons after fractures of the distal radius. J Hand Surg Am 24:121-132

7. Pogue DJ, Viegas SF, Patterson RM, Peterson PD, Jenkis DK, Sweo TD, Hokanson JA (1990) Effects of distal radius fracture malunion on wrist joint mechanics. J Hand Surg Am 15:721-727

8. Hirahara H, Neale PG, Lin YT, Cooney WP III, An KN (2003) Kinematic and torque-related effects of dorsally angulated distal radius fractures and the distal radial ulnar joint. J Hand Surg Am 28:614-621

9. Simic PM, Weiland AJ (2003) Fractures of the distal aspect of the radius: changes in treatment over the past two decades. Instr Course Lect 52:185-195
10. Chung KC, Shauver MJ, Birkmeyer JD (2009) Trends in the United States in the treatment of distal radial fractures in the elderly. J Bone Joint Surg Am 91:1868-1873

11. Tan V, Capo JT, Warburton M (2005) Distal radius fracture fixation with an intramedullary nail. Tech Hand Up Extremity Surg 9:195-201

12. Tarr RR, Wiss DA (1986) The mechanics and biology of intramedullary fracture fixation. Clin Orthop Relat Res 212:10-17

13. Müller ME (1987) Distal Radius. In: Müller ME, Nazarian S, Koch P, Schatzker J (eds) AO classification of fractures. Springer, Berlin, pp 106-115

14. McGrory B, Amadio P (1998) Malunion of the distal radius. In: Cooney W, Linscheid R, Dobyns J (eds) The wrist: diagnosis and operative treatment. Mosby, St. Louis, pp 365-384

15. Fernandez DL (1982) Correction of posttraumatic wrist deformity in adults by osteotomy, bone grafting, and internal fixation. J Bone Joint Surg Am 64:1164-1178

16. Bell JSP, Wollstein R, Citron ND (1998) Rupture of flexor pollicis longus tendon: a complication of volar plating of the distal radius. J Bone Joint Surg Am 80:225-226

17. Rozental TD, Beredjiklian PK, Bozentka DJ (2004) Functional outcome and complications following two types of plating for unstable fractures of the distal radius. J Bone Joint Surg Am 86:1956-1960

18. Berglund LM, Messer TM (2009) Complications of volar plate fixation for managing distal radius fractures. J Am Acad Orthop Surg 17:369-377

19. Jupiter JB, Fernandez DL (2002) Complications following distal radial fractures. Instr Course Lect 51:203-219

20. Brooks KR, Capo JT, Warburton M, Tan V (2006) Internal fixation of distal radius fractures with novel intramedullary implants. Clin Orthop Relat Res 445:42-50

21. Ilyas AM (2009) Intramedullary fixation of distal radius fractures. J Hand Surg Am 34:341-346

22. Tarallo T, Mugnai R, Adani R, Catani F (2014) Malunited extraarticular distal radius fractures: corrective osteotomies using volar locking plate J Orthopaed Traumatol 15:285-290

23. Graham T (1997) Surgical correction of malunited fractures of the distal radius. J Am Acad Orthop Surg 5:270-281

24. Ring D, Roberge C, Morgan T, Jupitor JB (2002) Osteotomy for malunited fractures of the distal radius: a comparison of structural and nonstructural autogenous bone grafts. J Hand Surg Am 27:216-222

25. Arrington ED, Smith WJ, Chambers HG, Bucknell AL, Davino NA (1996) Complications of iliac crest bone graft harvesting. Clin Orthop Relat Res 329:300-309

26. Malone KJ, Magnell TD, Freeman DC, Boyer MI, Placzek JD (2006) Surgical correction of dorsally angulated distal radius malunions with fixed angle volar plating: a case series. J Hand Surg Am 31:366-372

27. Sato $K$, Nakamura $T$, Iwamoto $T$, Toyama $Y$, Ikegami $H$, Takayama S (2009) Corrective osteotomy for volarly malunited distal radius fracture. J Hand Surg Am 34:27-33

28. Mahmoud M, El Shafie S, Kamal M (2012) Correction of dorsally-malunited extra-articular distal radial fractures using volar locked plates without bone grafting. J Bone Joint Surg $\mathrm{Br}$ 94:1090-1096

29. Fernandez DL (1993) Malunion of the distal radius: current approach to management. Instr Course Lect 42:99-113

30. Capo John T, Hashem Jenifer (2010) Treatment of extra-articular distal radial malunions with an intramedullary implant. J Hand Surg Am 35:892-899 